\title{
Companies' efforts towards reduction, reuse, recycling and recovery (4Rs) of e-waste
}

\author{
B. Krumay \& R. Brandtweiner \\ Institute for Information Management and Control, WU Vienna, Austria
}

\begin{abstract}
The e-waste pile is constantly increasing, 41.8 million tons e-waste was generated in 2014 and prognosis shows there will be further increases. On one hand, technological reasons for discarding electronic devices, such as life cycles of products is an explanation for e-waste. However, non-technological reasons like lifestyle-indicated rebuying or psychological obsolescence lead in addition to more and more replacement of electronic devices - especially mobile devices before they have reached their end-of-life. Furthermore, products that are designed with short life spans with the intention of generating frequent repurchases (planned obsolescence) are supplementary drivers for the increase of the e-waste pile. Since companies nowadays depend highly on the usage of computers, they of course contribute to the e-waste generated by private users. In this paper, however, we specifically focus on companies' approach towards reducing, reusing, recycling and recovery (4Rs) of e-waste. Based on interviews with managers, responsible for companies' e-waste handling, we identify different approaches towards these 4Rs. As a result, we see that companies' approaches towards reduction of e-waste are mainly targeting towards prolonging the life spans of computers, driven by costs evolving from replacement. Reuse, however, is an issue which is shifted to partners and experts outside the companies. The same is true for recycling and refurbishment. We identified different categories of ICT products, which are replaced more likely before reaching end-of-life, in particular smartphones. Concerning peripheral ICT hardware (printers, projectors), other triggers, e.g. energy efficiency of newer devices or new technologies, dominate the reasons for replacement. Based on the so-gained insights, we depict the results in a matrix of the current approaches towards 4Rs of e-waste in business.
\end{abstract}

Keywords: e-waste, $4 R s$, reduce, reuse, recycling, recovery, life span. 


\section{Introduction}

Electronic waste or e-waste is one of the scourges of humanity. Living without electronic devices seems to be impossible in the developed world - with severe consequences. At the end-of-life, electronic devices add up to a huge pile of e-waste. However, the computerization and further increase of mobile devices as well as the integration of computer hardware into non-computer products (e.g. cars) to realize connectedness between different components constantly multiplies the amount of e-waste. In addition, short life cycles, lifestyle-connected rebuys and the fast development of new technologies speed up this trend. The frightening impacts on the environment and society are the depletion of rare metals, pollution of the environment and poisoning of people living close to e-waste landfills, to name just a few. Although the e-waste topic has found attention in research and public authorities, this consideration mainly focuses on the environmental, economic and social impacts in countries - often developing countries - where the electronic devices are dismantled [1-3]. To date, only a few studies have investigated how organizations handle this issue. The focus so far was on the responsibility of producers [4-6], however, organizations using computers also have a responsibility. Consequently, our research serves as a starting point to understand how organizations tackle the e-waste problem. We rely on concepts, stemming from the corporate social responsibility (CSR) and business ethics research community and focus on the awareness of organizations for their responsibility towards e-waste. We conducted interviews, revealing organizations' approaches towards reduction, reuse, recycling and recovery of e-waste. Our main question therefore is: how do companies adopt their responsibility for the e-waste they generate. The rest of the paper is structured as follows: first, we give a brief introduction into the state of the field, second we explain our methodological approach, followed by results of our studies. Finally, we discuss the results and show their contribution to research, society and business. We finish this paper with a sound conclusion, limitations and further research possibilities.

\section{State of the field}

All over the world, the so-called Information Society [1] depends on computers, providing the highly valuable resource of information, but at a high price: the necessary hardware is produced mainly in low-income countries where environmental protection is often not an issue [2, 3]. Furthermore, computers require scarce and precious resources (e.g. gold and tantalum), mined under miserable working conditions [2, 4]. While using computers, the energy used generates greenhouse gas emissions [5]. Besides production and usage, the disposal in the form of e-waste shows even more impacts that are negative. The far-reaching consequences of e-waste can be found in at least two dimensions: time [6] and space [7]. In terms of time, disposed e-waste may produce hazardous substances, leaking into the soil, which returns into the food chain via polluted ground water, finally poisoning nutrition over time [8-11]. The spatial problem refers to the fact that computers having reached their end-of-life are shipped to developing countries, 
masqueraded as donations to avoid disposal costs [7, 12-14]. Once in the country, the computers are destroyed and cannibalized: rare and precious materials are excavated, the rest is disposed or burned, leading to heavy pollution of the air [7, $11,15]$. In addition, the excavation takes place without preventive measures, being suspect to causing cancer and low life expectancy $[8,15,16]$. Although regulations and voluntary initiatives are in place, they are often evaded [17]. Unfortunately, the amount of electronic waste (e-waste) is further increasing. According to a report published by the European Commission in 2005, 9 million tons of e-waste have been generated and 12 million tons are forecasted for the year 2020 [13]. When talking about electronic waste (e-waste) or waste evolving from electrical and electronic equipment (WEEE) every pieces of hardware used in private households and business, from washing machines, TV sets to computers is part of it [7]. The EU e-waste guideline 2012/12/EU [18], for example, names ten different categories, but excludes large-scale electronic plants. However, in the business context the term e-waste especially refers to ICT products respectively goods including microchips, whereas WEEE is more general and includes white goods, too. However, these borders become blurry, since microchips are integrated for communication with each other into non-ICT products (e.g. cars, refrigerators).

In general, devices become e-waste when they are discarded [7] due to technological, business or other reasons. Technological and business reasons for discarding ICT products include replacement by better and faster technologies, deterioration, or incompatibility with new software requirements, to name just a few [19-21]. Furthermore, products which are designed with a short life-span and the intention to convince consumers to frequent repurchases (planned obsolescence) [22] lead to discarding. For example, the life span of a central processing unit (CPU), used in every computer, decreased from six to four years between 1997 and 2005 [13]. Other reasons to discard devices are lifestyle indicated rebuy or psychological obsolescence [20,23]. This is the felt need of users to replace a device due to non-technical reasons. Smartphones, especially, are replaced long before they reached their technological end-of-life [24]. When an electronic product is discarded due to not fitting the needs anymore, it can be reused as is by other users with other needs and does not become e-waste [7]. However, when the technological end-of-life has been reached, recycling, recovery, refurbishment and disposal are possibilities to handle the devices $[11,25,26]$. Possibilities of recycling, refurbishment and recovery, however, depend on how the devices are built, as some designs do not allow reassembling, making them inefficient or even dangerous [7, 10, 11, 27]. Thus, green or eco-design of ICT products - designing devices in a modular, environmentally friendly way - is a precondition for achieving e-waste reduction [10]. The 4Rs - reduction, reuse, recycling, and recovery - are not new in the field of waste management, but, e-waste studies targeting towards the 4Rs can rarely be found [28].

\section{Methodological approach}

To examine how companies tackle e-waste, we conducted open qualitative interviews to explore relevant issues from the interviewee's perspective $[37,38]$. 
To identify characteristics and explore patterns we used thematic analysis. With this approach, one is able to evaluate the manifest content of statements. This requires condensing the interview information via a structured summary and making the interviews comparable without neglecting their specificities [39]. We conducted semi-structured topical interviews with managers responsible for e-waste in January 2015. Based on literature we designed an interview guideline with pre-defined topics. Thus, we were able to embrace the whole subject area in accordance with the research question [40]. The pre-defined topics include (a) e-waste (what is it, how much is allocated at your company, how long are the life cycles of devices, does green design influence buying decision?), (b) end-oflife handling (what is happening to the devices at the end of life?), and (c) responsibility for e-waste (who is/should be responsible for e-waste?). Moreover, the interviewers encouraged the interviewees to further explain their thoughts by keeping the interview open [37]. The interviews were audio-recorded, transcribed and analysed. All interviews were conducted in the native language of the interviewees and interviewers. We used the software Atlas.ti for coding and analysis. Two researchers were involved in the coding process. The coding process was led by the topics of the interview guidelines. In the course of the analysis, we developed categories from the interviews.

Interviews were conducted on the phone and face-to-face. The interview length was between 22 and 47 minutes. Concerning their position in the company, one interviewee is technical manager, responsible for all technical equipment (I1), the second is a chief information officer (CIO) and chief financial officer (CFO) and the third one is a CIO. All interviewees have been in the companies for several years and in the current position for at least five years. The companies are operating in different industries and are of different size. Table 1 summarizes the characteristics of interviewees and the interview situation.

Table 1: Details of interviews and interviewees.

\begin{tabular}{|l|c|c|c|}
\hline & I1 & I2 & I3 \\
\hline Duration (min.) & 35 & 47 & 22 \\
\hline Type & Phone & Face-to-face & Phone \\
\hline Position & Technical Manager & CIO and CFO & CIO \\
\hline In the company since & 2003 & 2005 & 2005 \\
\hline In this position & 2008 & 2010 & 2005 \\
\hline Industry & Media & Pharmaceutical & IT Services \\
\hline Employees (approx.) & 400 & 110 & 25 \\
\hline
\end{tabular}

\section{Results}

The results developed from the interviews revealed important issues concerning e-waste handling. Interviewees showed a very clear understanding what e-waste is: from their point of view, it is waste evolving from the end-of-life of computers (servers, personal computers, mobile devices) and peripheral components (printers, monitors, input devices, network equipment). They explicitly excluded 
other technical equipment used in the production (I2) and household machines (I1, I2, I3) used in the office (e.g. coffee machines, refrigerators, microwave ovens). The life span of ICT products in terms of usage in the company ranges from two years for mobile devices, four years for network equipment, and about five years or more for other devices. The interviewees reported that most employees have their own personal computers or laptops, some employees have mobile devices (i.e. smartphones, tablets). Concerning servers, the companies are very different. Whereas in I1 it has been reported that they operate about 100-120 servers in house and outside the company, in I2 it was reported that they hardly have 10 servers in house, since they started to virtualize them. Finally, I3 stated that they have three servers for their own administration, but run up to 200 servers for their customers, which they also purchase and maintain, depending on the contracts.

\subsection{Discarding of devices}

Concerning ICT products, different groups, like small mobile devices (e.g. mobile and smart phones, tablets), personal computers (including notebooks and fixed PCs) and servers have been identified. Some peripheral devices (i.e. monitors, input devices) are experienced as computer-attached devices, whereas others (i.e. printers, projectors) are seen as shared devices. In addition, network equipment (e.g. routers, hubs, WIFI access points) has been mentioned. The interviewees clearly differentiated between devices with short (e.g. smart phones) and long (e.g. servers) life spans. Furthermore, interviewees expressed various reasons for discarding devices. Technological reasons include that the device is obviously broken (Broken), does not work appropriately without any detectable reason (Not working approp.), newer technology is available (New technology), or new software requires high-performance hardware (New requirements) and existing hardware has to be replaced by "current but approved technology" (I2). Especially when devices do not work appropriately without any detectable reason, interviews experienced it as planned obsolescence. However, interviewees expressed the necessity to differentiate between unusable (broken) and usable devices, which are "suitable for private use but do not fit the business requirements we have" (I2). One interviewee (I1) reported that they rent printers; hence, the rental company is responsible for maintenance, repair and disposal.

Business reasons for discarding are end of maintenance of devices (End of maintenance), the expectation that new devices are more efficient (Efficiency), or having reached re-investment cycles (Investment cycle). It has been stated that hardware life cycles in the company depend not only on technology, but also on investment cycles to avoid "hardware investment peaks" (I2). Other reasons are users felt the need to have new devices (user-driven) or organizational issues (organizational) such as restructuration of the company (a) e.g. after a merger or (b) when companies move to new offices. Terms in brackets refer to the codes used in Table 2, which shows detailed information.

Based on the interviews, we identified some reasons for discarding devices to be common $(\mathrm{C})$, occur sometimes $(\mathrm{S})$ or hardly $(\mathrm{H})$. Common reasons for discarding devices are marked grey in the table. Especially small mobile devices are often not replaced due to technological or business reasons, but based on users 
feeling the need to replace the device. Servers, personal computers, network equipment and computer attached devices are mainly discarded due to technological reasons, whereas printers and projectors are commonly replaced due to business reasons.

Table 2: $\quad$ Device types, life span and reasons for discarding.

\begin{tabular}{|c|c|c|c|c|c|c|c|c|c|c|}
\hline & & \multicolumn{4}{|c|}{ Technological } & \multicolumn{3}{|c|}{ Business } & \multicolumn{2}{|c|}{ Other } \\
\hline Device type & 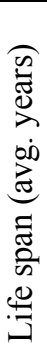 & $\begin{array}{l}\frac{D}{0} \\
\frac{D}{0} \\
0\end{array}$ & 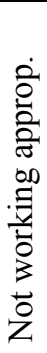 & $\begin{array}{l}\text { के } \\
0 \\
0 \\
0 \\
0 \\
0 \\
0 \\
0 \\
z \\
0 \\
z\end{array}$ & 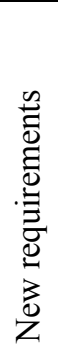 & 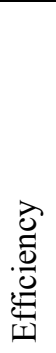 & 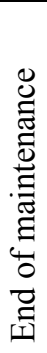 & 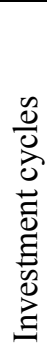 & 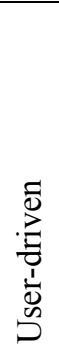 & 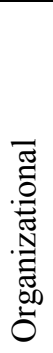 \\
\hline Small mobile devices & 2 & $\mathrm{~S}$ & $\mathrm{H}$ & $\mathrm{H}$ & $\mathrm{H}$ & $\mathrm{H}$ & $\mathrm{H}$ & $\mathrm{H}$ & $\mathrm{C}$ & - \\
\hline Personal computers & 5 & $\mathrm{~S}$ & $\mathrm{H}$ & $\mathrm{H}$ & $\mathrm{C}$ & $\mathrm{H}$ & $\mathrm{H}$ & $\mathrm{S}$ & $\mathrm{H}$ & $\mathrm{a}$ \\
\hline Servers & 5 & $\mathrm{~S}$ & $\mathrm{~S}$ & $\mathrm{C}$ & $\mathrm{C}$ & $\mathrm{S}$ & $\mathrm{H}$ & $\mathrm{S}$ & $\mathrm{H}$ & $\mathrm{b}$ \\
\hline Network equipment & 4 & $\mathrm{~S}$ & $\mathrm{H}$ & $\mathrm{C}$ & $\mathrm{C}$ & $\mathrm{H}$ & $\mathrm{H}$ & $\mathrm{H}$ & $\mathrm{H}$ & $\mathrm{b}$ \\
\hline $\begin{array}{l}\text { Computer-attached } \\
\text { devices }\end{array}$ & 5 & $\mathrm{C}$ & $\mathrm{S}$ & $\mathrm{S}$ & $\mathrm{H}$ & $\mathrm{S}$ & $\mathrm{H}$ & $\mathrm{H}$ & $\mathrm{S}$ & $\mathrm{a}$ \\
\hline Shared devices & 5 & $\mathrm{H}$ & $\mathrm{H}$ & $\mathrm{S}$ & $\mathrm{H}$ & $\mathrm{C}$ & $\mathrm{C}$ & $\mathrm{S}$ & $\mathrm{H}$ & $\mathrm{b}$ \\
\hline
\end{tabular}

\subsection{Reduction, reuse, recycling and recovery of e-waste}

In the interviews, we identified different approaches to reduce, reuse, recycle and recover e-waste. In general, the interviewees clearly differentiated between reuse and reduction, although reuse clearly also reduces e-waste. By contrast, interviewees did not differentiate between recycling and recovery of e-waste.

Concerning reduction, the most prominent approach in all interviews was to prolong life span of devices, achieved by buying reliable and repairable devices as well as by appropriate and regular maintenance. In addition, some organizational measures, such as replacement policies or buying standardized hardware have been mentioned. To prolong life span within the company, one interviewee (I2) mentioned that personal computers are shifted between employees when they become unusable for one task (e.g. requiring high performance), but are still suitable for other tasks.

Processes at the end-of-life of devices described in the interviews are quite similar. In general, devices having reached end-of-life from the company's point of view (unusable for business) are prepared for discard - removing all data stored on the device - and collected at a specific storage. Next steps depend on the devices' state - is it reusable or unusable. Concepts for reusable devices include selling devices or using as spare. Mobile devices especially are sold with the help of intermediaries on the market, since "mobile devices are of value, it is waste that 
brings money" (I1). In addition, two interviewees mentioned that the company had sold usable devices - not only mobile devices - to their employees on an "internal flea market" (I2). Other reusable devices are stored as a whole or disassembled in parts, which can be reused as spare parts for devices of the same type.

Concerning unusable devices which have no market value, companies rely on waste specialists. The specialists take over the responsibility for all devices collected from the company and identify the state of the device. The specialists decide which devices can be recycled or recovered and which have to be disposed of. All three interviewees expressed the need to know what happens to the devices. They emphasized their responsibility to select an appropriate partner company, who is "reliable, trustworthy and provides a high level of transparency" (I2). Shared devices are somehow different, since they - especially printers - are often not owned by the companies and take back by the sellers has been guaranteed in contracts, leading to refurbishment of the products.

Table 3: $\quad 4$ Rs and device types.

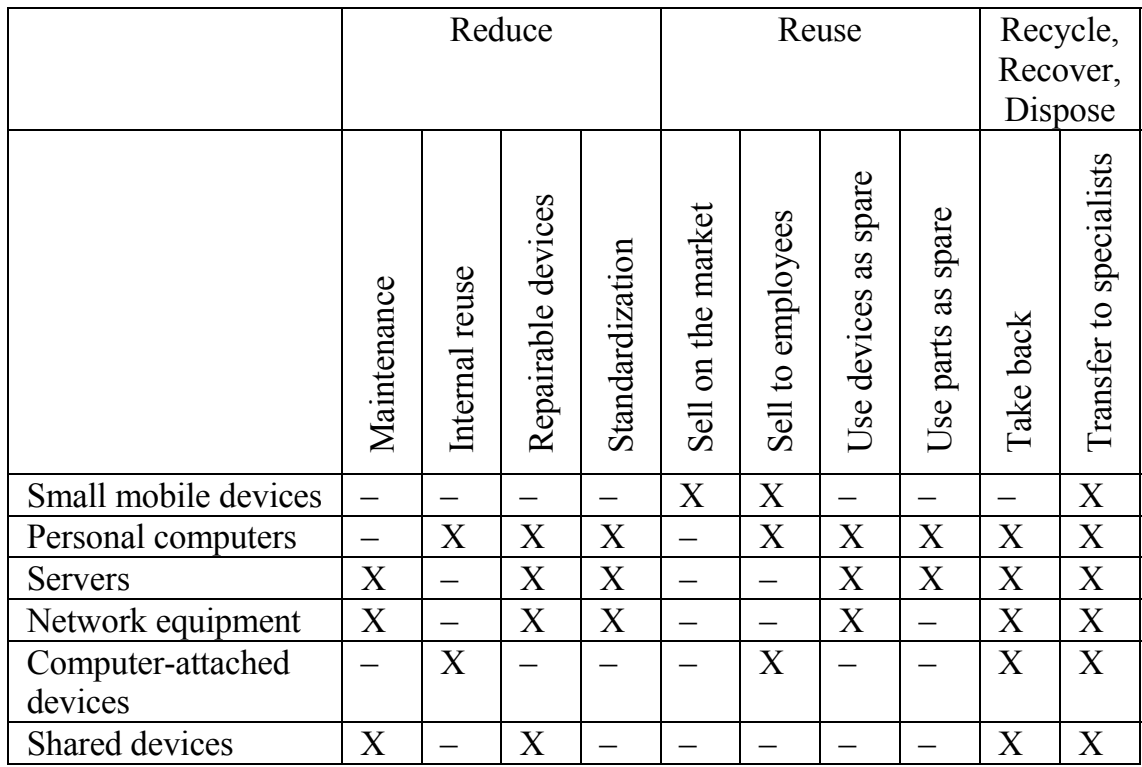

\section{Discussion}

With this study we want to explore how companies handle e-waste. To clarify the issue, it is first necessary to understand how companies define e-waste, which reasons exist to discard devices and which measures are in place to reduce, reuse, recycle and recover e-waste. In general, we identified that companies define e-waste rather similarly as waste evolving from the end-of-life of computer devices.

However, companies discard computers due to different reasons already before the devices have reached their end of life, depending on the device type and 
technological, business and other considerations. Approaches to reduce, reuse, recycle and recover e-waste are rather similar in the companies in our sample, but different again for different device types. Based on the interviews, we gained first insights into this topic and want to discuss the results from different points of view.

As we have seen, different device types are handled differently concerning reasons for discarding and handling. Small mobile devices (i.e. mobile phones, smart phones, tablets) are very specific as they have a relatively short life span ( 2 years) and are used one per employee. Moreover, discarding is primarily triggered by user demands. In addition, efforts to reduce e-waste or prolong their life span do not apply for small mobile devices. Considerations to buy more standardized, reliable or repairable mobile devices seem to be missing in the context of mobile devices. This may be due to the fact that mobile devices are lifestyle products and most prone to psychological obsolescence [20, 23], as already discussed in other studies $[24,29]$. This is in line with e-waste numbers: almost $15 \%$ of e-waste created in 2014 were mobile devices [30]. Only reuse due to the market value seems to tackle this issue, however, this market value exists because they are discarded before reaching their end-of-life. Another very specific device type are shared devices, as the business reasons are commonly triggering discarding. This may be due to the fact that they are not critical for the business, can easily be replaced and do not contribute to companies' value creation. In addition, companies do not own but rent them and thus maintenance contracts are steering the replacement. However, they are very specific in two aspects: first, efficiency plays an important role for shared devices, since the interviewees have directly addressed the energy efficiency of printers. Second, the possibility that suppliers take back devices for refurbishment has exclusively been mentioned for printers. We conclude that companies shift their responsibility for e-waste for shared devices to the suppliers. Finally, devices such as personal computers (including notebooks), servers, computer-attached devices and network equipment share characteristics. First, the life span is about 4-5 years; second, technological reasons are triggering discarding and third, reduction and reuse efforts influence those most. We conclude that companies focus on those devices since they bring the most value for the company or at least keep the business up and running. As stated above, computers are a precondition for companies' competitiveness in the information society [1].

When looking at the companies' efforts to apply the 4Rs, we see that companies adopt responsibility for reducing e-waste, whereas the other Rs are mainly outside the companies' scope. Reduce e-waste is connected to buying decisions and attributes of the devices, including quality, standardization and possibilities to repair the device. All three target towards prolongation of life span, supported by appropriate maintenance whereas quality has to do with trust in the supplier and standardization targets towards the possibility to use 'old' systems as spare parts. Concerning repairability, in contrast to everything said above. This also occurs in the context of smartphones, maybe because issues on smartphone modularity and repairability have been in the media lately. Interestingly, green design has not been reported as an influencing factor for buying decisions. Although one interviewee (I1) stated that this is not an issue, because buying decisions are influenced by 
many other factors (e.g. price, compatibility, security and future proof devices), interviewee two (I2) mentioned the lack of labelling to be able to integrate green design into this decision. Interviewee three (I3) even expressed the need to have regulations or benefits, supporting companies in their efforts to reduce e-waste. Although energy efficiency labels are well known, they influence purchase decisions only when "hardware offerings are similar in all other points" (I2). Although companies are aware of Life Cycle Analysis (LCA) of products, they have never considered an LCA as the basis for a purchase criterion. Whereas reduction is directly connected to internal measures before or during the life span of computers in the company, reuse, recycling and recovery are clearly located beyond the scope of the companies and their e-waste management. Efforts to reuse, buy, sell devices or use them as spare parts show that they feel implicitly responsible for them [31]. Outside the companies, partners specialised in recycling and recovery or intermediaries, selling usable devices on the market, take over this responsibility. Companies utilize all possibilities before disposal of devices to reduce e-waste, but some decisions are shifted to partner companies. Interestingly, all interviewees connected the term e-waste to issues being published in the media. The main aim is to avoid that their devices "pop up in one of these illegal landfills" (I2) to not run into problems like loss of reputation [32, 33]. Consequently, the interviewees underlined their efforts for selecting the right partner with high standards and transparent processes.

Based on the above stated discussion, our work contributes to the current discussion in different ways. Firstly, we provide a basic understanding on how e-waste is seen in companies and integrate it into the current research on e-waste $[13,34]$. Our research is a first step for clarifying approaches towards reduction, reuse, recycling and recovery of e-waste. This also contributes to the current sustainability discussion, which has slowly found its way into research disciplines beyond business ethics [35]. Secondly, with our research we contribute to practice since we provide first insights into companies' approach to e-waste handling. By describing a general process and identifying reasons for discarding ICT, this research may serve as a rough guide for business. In addition, we show concepts inside and outside the companies, which may foster as an example for other companies.

\section{Conclusions, limitations and further research}

In this research, we provide insights into e-waste handling of a rather small sample of companies. The companies are located in very different industries, are of different sizes and produce different amounts of e-waste. However, their e-waste approaches, processes, reasons for discarding ICT devices and life spans of hardware are surprisingly similar. It becomes observable that all three companies adopt responsibility for e-waste, but with some constraints and restrictions. The differentiation between device types, the concepts for usable and valuable devices as well as finding that the reduction of e-waste is more located in the company, whereas the other Rs being shifted to partners are new and will hopefully start a discussion. Obviously, this research has some limitations. Firstly, the interviews 
are not representative; not for companies nor for the industry. Secondly, the interviews are strongly influenced by the experience the interviewees have. Thirdly, all companies in the sample are located in the same country and therefor share the same external conditions. Based on these limitations, our future research direction is clear: extending the basis by conducting additional interviews to be able to develop a deeper understanding on e-waste handling in companies.

\section{References}

[1] OECD, Measuring the Information Economy 2002, OECD, Editor. 2002, OECD.

[2] Veale, E., Is there Blood on your Hands-Free Device: Examining Legislative Approaches to the Conflict Minerals Problem in the Democratic Republic of Congo. 2013.

[3] Schwarzer, S., De Bono, A., Giuliani, G., Kluser, S. \& Peduzzi, P., E-waste, the hidden side of IT equipment's manufacturing and use. 2005.

[4] Marks, P., Blood Minerals. New Scientist, 222(2973), pp. 1-22, 2014.

[5] Malmodin, J., Moberg, Å., Lundén, D., Finnveden, G. \& Lövehagen, N., Greenhouse gas emissions and operational electricity use in the ICT and entertainment \& media sectors. Journal of Industrial Ecology, 14(5), pp. 770-790, 2010.

[6] Conrad, R., Background document on recycling waste from computers, A. Environment, Editor. 2000, Alberta Environment: Alberta.

[7] Widmer, R., Oswald-Krapf, H., Sinha-Khetriwal, D., Schnellmann, M. \& Böni, H., Global perspectives on e-waste. Environmental Impact Assessment Review, 25(5), pp. 436-458, 2005.

[8] Zhao, G., Wang, Z., Zhou, H. \& Zhao, Q., Burdens of PBBs, PBDEs, and PCBs in tissues of the cancer patients in the e-waste disassembly sites in Zhejiang, China. Science of the total environment, 407(17), pp. 4831-4837, 2009.

[9] Shah, A., Christian, T., Patel, C.D., Bash, C. \& Sharma, R.K., Assessing ICT's Environmental Impact. IEEE Computer, 42(7), pp. 91-93, 2009.

[10] Murugesan, S., Harnessing green IT: Principles and practices. IT professional, 10(1), pp. 24-33, 2008.

[11] Streicher-Porte, M., Widmer, R., Jain, A., Bader, H.-P., Scheidegger, R. \& Kytzia, S., Key drivers of the e-waste recycling system: Assessing and modelling e-waste processing in the informal sector in Delhi. Environmental Impact Assessment Review, 25(5), pp. 472-491, 2005.

[12] Nnorom, I.C. \& Osibanjo, O., Electronic waste (e-waste): Material flows and management practices in Nigeria. Waste Management, 28(8), pp. 14721479, 2008.

[13] Babu, B.R., Parande, A.K. \& Basha, C.A., Electrical and electronic waste: a global environmental problem. Waste Management \& Research, 25(4), pp. 307-318, 2007.

[14] Wong, M., Wu, S., Deng, W., Yu, X., Luo, Q., Leung, A., Wong, C., Luksemburg, W. \& Wong, A., Export of toxic chemicals-a review of the 
case of uncontrolled electronic-waste recycling. Environmental Pollution, 149(2), pp. 131-140, 2007.

[15] Feldt, T., Fobil, J.N., Wittsiepe, J., Wilhelm, M., Till, H., Zoufaly, A., Burchard, G. \& Göen, T., High levels of PAH-metabolites in urine of ewaste recycling workers from Agbogbloshie, Ghana. Science of the Total Environment, 466, pp. 369-376, 2014.

[16] Ni, H.G., Zeng, H., Tao, S. \& Zeng, E.Y., Environmental and human exposure to persistent halogenated compounds derived from e-waste in China. Environmental Toxicology and Chemistry, 29(6), pp. 1237-1247, 2010.

[17] Waste Electrical and Electronic Equipment (WEEE); European Commission.

[18] European Parliament, Directive 2012/19/EU of The European Parliament and of the Council of 4 July 2012 on Waste Electrical and Electronic Equipment (WEEE). 2012.

[19] Van den Ende, J. \& Dolfsma, W., Technology-push, demand-pull and the shaping of technological paradigms - Patterns in the development of computing technology. Journal of Evolutionary Economics, 15(1), pp. 8399, 2005.

[20] Slade, G., Made to break: Technology and obsolescence in America. Harvard University Press. 2009.

[21] Prasad, P.J., Information communication technology (ICT)-its waste and consequences. International Journal of Environmental Technology and Management, 15(3), pp. 363-376, 2012.

[22] Bulow, J., An economic theory of planned obsolescence. The Quarterly Journal of Economics, pp. 729-750, 1986.

[23] Cooper, T., Inadequate life? Evidence of consumer attitudes to product obsolescence. Journal of Consumer Policy, 27(4), pp. 421-449, 2004.

[24] Dowling, S., Paxton, N. \& Hoover, J., Apple Press Info. 2014.

[25] Chi, X., Streicher-Porte, M., Wang, M.Y. \& Reuter, M.A., Informal electronic waste recycling: a sector review with special focus on China. Waste Management, 31(4), pp. 731-742, 2011.

[26] Cairns, C.N. E-waste and the consumer: improving options to reduce, reuse and recycle. Electronics and the Environment, 2005. Proceedings of the 2005 IEEE International Symposium on. IEEE. pp. 237-242. 2005.

[27] Kahhat, R., Kim, J., Xu, M., Allenby, B., Williams, E. \& Zhang, P., Exploring e-waste management systems in the United States. Resources, Conservation and Recycling, 52(7), pp. 955-964, 2008.

[28] Lertchaiprasert, P. \& Wannapiroon, P., Study of e-Waste Management with Green ICT in Thai Higher Education Institutions. International Journal of e-Education, e-Business, e-Management and e-Learning, 3(3), p. 239, 2013.

[29] Zink, T., Maker, F., Geyer, R., Amirtharajah, R. \& Akella, V., Comparative life cycle assessment of smartphone reuse: repurposing vs. refurbishment. The International Journal of Life Cycle Assessment, 19(5), pp. 1099-1109, 2014. 
[30] Baldé, C.P., Wang, F., Kuehr, R. \& Huisman, J., The global e-waste monitor - 2014, in IAS - SCYCLE, U.N. University, Editor. 2015, United Nations University: Bonn, Germany.

[31] Matten, D. \& Moon, J., "Implicit" and "explicit" CSR: a conceptual framework for a comparative understanding of corporate social responsibility. The Academy of Management Review ARCHIVE, 33(2), pp. 404-424, 2008.

[32] Lee, H., Lee, J. \& Kang, M.S. Does Satisfaction Make Customers Repurchase Same Brand Again? Allied Academies International Conference. Academy of Marketing Studies. pp. 40-44. 2010.

[33] Fombrun, C.J., A world of reputation research, analysis and thinking building corporate reputation through CSR initiatives: evolving standards. Corporate Reputation Review, 8(1), pp. 7-12, 2005.

[34] Agarwal, S. \& Nath, A. Green computing - a new horizon of energy efficiency and electronic waste minimization: a global perspective. Communication Systems and Network Technologies (CSNT). IEEE. pp. 688-693. 2011.

[35] Anderson, M.W., Teisl, M. \& Noblet, C., Giving voice to the future in sustainability: Retrospective assessment to learn prospective stakeholder engagement. Ecological Economics, 84, pp. 1-6, 2012. 